\title{
Influence of different cosmetic vehicles in mechanical and physical properties of hair treated with oxidative hair dyes
}

\author{
Elaine Cabral Serrão ${ }^{1}$, Robson Miranda da Gama ${ }^{1,2,3^{*}}$, Michelli Ferrera Dario ${ }^{1}$, Simone Aparecida \\ da França-Stefoni' ${ }^{1}$, Valcinir Bedin ${ }^{4}$, André Rolim Baby ${ }^{1}$, Maria Valéria Robles Velasco ${ }^{1}$ \\ ${ }^{1}$ Department of Pharmacy, School of Pharmaceutical Sciences, University of São Paulo, São Paulo, SP, Brazil, \\ ${ }^{2}$ School of Pharmaceutical Sciences. Faculty Medicine ABC, Santo André, SP, Brazil, ${ }^{3}$ School of Pharmacy, Santo Amaro \\ University, São Paulo, SP, Brazil, ${ }^{4}$ BWS Graduate Institute of São Paulo, São Paulo, SP, Brazil
}

\begin{abstract}
Hair care products play a significant role in the cosmetic market and aim at improving hair brightness, breakage resistance, and color change. In this study, we analyzed the possibility of the formulation of oxidative dyes in different vehicles impacting the hair's both mechanical and physical properties. Light brown and light blond dyes were prepared using eight different vehicles. Among these, four vehicles were emulsifying agents and four gelling agents. Each formulation was applied to two types of virgin Caucasian hair (light blond and dark brown). Physical, chemical, and organoleptic properties of each formulation were assessed, as well as changes in hair parameters after oxidative dyeing, such as staining intensity, brightness, and breaking strength. The parameters of color and brightness differed in some formulations, but the hair type also responded differently. Brightness parameter was increased in dark brown hair colored with both dyes, whereas light blond hair showed the opposite result. Regarding the breaking strength, there were no significant differences between the two kinds of tresses. Cosmetic formulations should adjust the consumer desired effects (e.g. color change) in order to present minimal drawbacks (e.g. decrease of hair brightness and strength). Thus, the study of different vehicles is important when establishing the best oxidative dye formulation.
\end{abstract}

Keywords: Hair dyes/analyse. Cosmetic technique/utilization. Hair/chemistry. Hair color. Hair/strength. Hair/bright.

\section{INTRODUCTION}

Hair dyes are widely used by both women and men for numerous reasons, such as dyeing and camouflage of gray hair in order to follow the trend of hair coloring fashion and to express their own personality (Harrison, Sinclair, 2003; França et al., 2015). Hair dyes can be classified according to color durability after the application on hair tresses by using the following types: temporary, semi-permanent, and permanent (França et al., 2015).

Data on hair anatomy and physiology is critical when studying the mechanisms of hair care cosmetics. The hair fiber can be divided into two components: root and shaft. The hair shaft contains three main structures: cuticle, cortex, and medulla. The cuticle is the outermost

*Correspondence: R. M. da Gama. Departmento de Farmácia, Faculdade de Ciências Farmacêuticas, Universidade de São Paulo. Avenida Prof. Lineu Prestes, $\mathrm{N}^{\circ} 580$, Bl. 13/15, Conjunto das Químicas, Cidade Universitária, 05508-900 São Paulo, SP, Brasil. E-mail: robson.gama@fmabc.br layer and its role is to protect the hair shaft against environmental and chemical damages. Surface properties (e.g. brightness and resistance to combing) are influenced by the cuticle scales orientation. The cortex is located below the cuticle and confers tensile strength and elasticity to the hair fiber due to its crystallized $\alpha$-keratin fibrils organization. The medulla, another component of the hair fiber, may or may not be present and its role is not clearly defined (Velasco et al., 2009; Alessandrini, Piraccini, 2016; Robbins, 2002).

The wide range of natural hair colors is determined by the total amount of melanin pigments (either eumelanin or pheomelanin, or a mixture of both) present in the cortex of the hair fiber. Hair color produced by melanin vary from brown to black (eumelanin) or yellow to red (pheomelanin). The melanin types determine not only the hair color, but also the chemical composition and physical arrangement of granules in the uniformity related to the distribution of melanin granules into the fiber (Tobin, 
2008; Liu et al., 2005). The function of the melanin granules is to effectively absorb light and to protect against damage hair, dark hair containing significantly more melanin than light hair.

Permanent oxidative hair dyes consist of highly reactive molecules which react in a strong alkaline/oxidant medium opening the cuticle, penetrating the hair, and originating colored polymers into the cortex (Shansky, 2007; França et al., 2015).

Permanent oxidative hair dye in fiber causes the formation of indo-dyes and forms colorless precursors with low molecular weight ( $p$-aminophenol and $p$-phenylenediamine). This occurs by oxidation with hydrogen peroxide under alkaline conditions. At this point, the precursors react with the couplers as $m$-aminophenols ( $m$-aminophenol, 4-amino-2-hydroxytoluene and 2,4-diaminophenoxyethanol) and $m$-diamines (resorcinol) which react to each other in strongly alkaline/oxidizing environment, yielding colored polymers (Corbett, 1984; Shansky, 2007).

During this process, alterations in the hair structure occur, potentially affecting its manageability, shine, and breaking strength (Gama et al, 2010). The formulation components may also have an influence on these factors.

Besides the pigmentation components, the correct choice of the vehicles during a hair dye formulation is important to obtain a stable and efficient product. Emulsions and gels are ubiquitous vehicles in cosmetic formulations. (Buchmann, 2001). An emulsion is a dispersion of two or more immiscible liquids that, with the use of an amphiphilic component (emulsifier), can form homogeneous substances. Emulsions have cleansing action, ease of application, and the ability to apply both water-soluble and oil-soluble ingredients at the same time (Kostansek, 2012). A gel consists of a dispersed system containing one gelling agent interpenetrated by a liquid, usually water or an aqueous-alcoholic mixture (Cai, Gupta, 2012). Thus, this study evaluates the impact of several emulsion or gel-based oxidative hair dyes formulations on physical and mechanical hair properties.

\section{MATERIAL AND METHODS}

\section{Hair dyes formulations preparation}

Eight hair dye formulations were prepared, four based on emulsion oil in water $(\mathrm{O} / \mathrm{A})$ vehicles and four on aqueous gel vehicles. Qualitative composition of emulsion formulations comprised anionic surfactant [Cetearyl Alcohol (and) Sodium Lauryl Sulfate (and) Sodium Cetearyl Sulfate (Lanette ${ }^{\mathrm{TM}} \mathrm{N}-\mathbf{L A N}$ ); Cetearyl
Alcohol (and) Dicetyl Phosphate (and) Ceteth-10 Phosphate (Crodafos ${ }^{\mathrm{TM}} \mathrm{CES}$ - CRO)]; or nonionic selfemulsifying wax [: Cetearyl Alcohol (and) Polysorbate 60 (Polawax NF ${ }^{\mathrm{TM}}$ - POL); Cetearyl Alcohol (and) Ceteareth-20 (Cosmowax ${ }^{\mathrm{TM}} \mathrm{J}-$ COS)]. The other ingredients of the formulations were: Cetearyl alcohol, caprylic/capric triglyceride, butylhydroxytoluene (BHT), water, propylene glycol and preservative blend (Phenoxyethanol (and) methylparaben (and) ethylparaben (and) butylparaben (and) propylparaben (and) isobutylparaben). Qualitative composition of gel formulations differed from the others only by the gelling agent and comprised anionic [Carbomer (Carbopol $^{\mathrm{TM}}$ 980 - CAR); Ammonium Acryloyldimethyltaurate (and) VP Copolymer (Aristoflex $\left.\left.{ }^{\mathrm{TM}} \mathrm{AVC}-\mathbf{A R I}\right)\right]$; or nonionic gels [Hydroxyethylcellulose (Natrosol ${ }^{\mathrm{TM}}$ - NAT) or Sclerotium gum (Amigel $\left.\left.{ }^{\mathrm{TM}}-\mathbf{A M I}\right)\right]$. The components used in all formulations comprised triethanolamine, water (aqua); propylene glycol and preservative blend (Phenoxyethanol (and) methylparaben (and) ethylparaben (and) butylparaben (and) propylparaben (and) Isobutylparaben).

Each emulsion or gel formulation was used to prepare two hair dyes colors (light blond and light brown), resulting in 16 formulations. The dyes were produced with pigments and other excipients obtained from Les Colorants Wackherr ( $\mathrm{LCW}^{\mathrm{TM}}$, Brazil). Qualitative composition of the Light brown dye formulation was: m-aminophenol (MAP), p-phenylenediamine (PPD), 2,4-diaminophenoxyethanol (2,4-DAPE), resorcinol $(R C N), t$-butyl hydroquinone (TBQ), erythorbic acid, tetrasodium EDTA, sodium metabisulfite, ammonium hydroxide. For the Light blond dye, the formulation was composed of $p$-aminophenol (PAP), 4-amino2-hydroxytoluene (AHT), resorcinol ( $R C N)$, sodium metabisulfite, tetrasodium EDTA, t-butyl hydroquinone (TBQ), erythorbic acid, ammonium hydroxide.

\section{Preparation of oxidative hair dyes}

Emulsion formulations LAN, CRO, POL, and COS were prepared by mixing the oily $(\mathrm{O})$ and aqueous phases (A) in different steel beakers. Both phases were warmed to $70.0 \pm 5.0^{\circ} \mathrm{C}$ on heating plates, and the oily phase was added to the aqueous phase until obtaining a homogenous emulsion by stirring (Kostansek, 2012). Each base was used to prepare both Light brown and Light blond hair dyes, resulting in eight emulsion-based formulations.

Concerning the gel formulations, each type of gelling agent has a particular way to be prepared. CAR and NAT have a similar way of preparation as hereby described: 
after warming water up to $70.0 \pm 5.0^{\circ} \mathrm{C}$, the gelling agent slowly dispersed while the mix is continuously stirred, avoiding forming clumps. After that, the other excipients were added slowly until the formulation is complete (Cai, Gupta, 2012). The $\mathrm{pH}$ of a CAR formulation was adjusted to 6.5-7.0. AMI gel preparations also required warmed water in the range of $60.0 \pm 5.0^{\circ} \mathrm{C}$, but the neutralization was not necessary. ARI gels were prepared with slowly addition of this gelling agent to the water phase (room temperature, non-warmed water required) and the system was stirred until to obtain a homogeneous system (Cai, Gupta, 2012). Each gelling agent was used to prepare both Light brown and Light blond hair dyes, resulting in eight gel-based formulations.

\section{Organoleptic characteristics of formulations}

Appearance, color, and odor 48 hours after preparation was assessed in comparison to time 0 (just after preparation). Furthermore, it was possible to verify if there was phase separation, and presence or absence of lumps, which allowed the primary product analysis (Brasil, 2008).

\section{$\mathrm{pH}$}

The $\mathrm{pH}$ determination was performed in Quimis ${ }^{\mathrm{TM}}$ pHmeter using undiluted samples (Brasil, 2008).

\section{Viscosity evaluation}

Viscosity determination (ViscoStar Marte ${ }^{\mathrm{TM}}$ Fungilab) was performed at room temperature (22.0 \pm $\left.5.0^{\circ} \mathrm{C}\right)$ using the following parameters: nonionic emulsions (POL and COS) with Spindle TR 10, rotation $50 \mathrm{rpm}$; anionic emulsions (LAN and CRO) with Spindle TR10, rotation $100 \mathrm{rpm}$; gels (anionic CAR, ARI and, nonionic NAT and, AMI) with Spindle R5, rotation $100 \mathrm{rpm}$. The measurements were registered in $\mathrm{mPa} \cdot \mathrm{s}^{-1}$ (miliPascal for second) after $1 \mathrm{~min}$ rotation (Brasil, 2008).

\section{Tresses preparation}

Caucasian virgin light blond and dark brown hair tresses (length: $20.0 \mathrm{~cm}$; weight: approximately $2.0 \mathrm{~g}$ ) were purchased from Bella Hair ${ }^{\mathrm{TM}}$ (Brazil). Each hair tress was first washed for $30 \mathrm{~s}$ with $15.0 \%(\mathrm{w} / \mathrm{v})$ sodium lauryl sulfate to remove impurities. All tresses were rinsed with warm $\left(37.0 \pm 5.0^{\circ} \mathrm{C}\right)$, distilled water in a constant flow of $240.0 \mathrm{~mL} \mathrm{~min}^{-1}$ for $1 \mathrm{~min}$. Next, they were dried at room temperature $\left(22.0 \pm 1.0^{\circ} \mathrm{C}\right)$ and relative humidity (RH 60 $\pm 5 \%$ ) for $12 \mathrm{~h}$ before performing further analysis (Gama et al, 2009; Gama et al, 2011).

\section{Application of hair dye}

When considering the hair dye treatment, $1.5 \mathrm{~g}$ of each dye formulation plus $1.5 \mathrm{~g}$ of emulsion commercial $\left(\mathrm{LBS}^{\mathrm{TM}}\right.$ ) containing $20.0 \%$ (v/v) hydrogen peroxide was applied to the tresses (Gama et al, 2009; Gama et al, 2011). After 40 minutes, the samples were washed as previously described. The samples were classified into four groups: Group I - Dark brown hair treated with light brown dye; Group II - Dark brown hair treated with light blond dye; Group III - Light blond hair treated with light brown dye; Group IV - Light blond hair treated with light blond dye.

\section{Mechanical properties}

From each group, five fibers measuring $10.0 \mathrm{~cm}$ each were used for mechanical properties tests. First, using a micrometer Mitutoyo ${ }^{\mathrm{TM}}$, the diameter was measured in three points (root, middle portion and tip) and the mean value was used later to calculate the hair fiber total area (Dario et al., 2013). The analysis of breaking strength was performed in Texturometer TAXT2 Analyzer ${ }^{\mathrm{TM}}$ model, operating at clutch speed traction of $300 \mathrm{~mm} / \mathrm{min}$, distance of $80 \mathrm{~mm}, 25.0 \mathrm{~kg}$ load and sensitivity of 0.49 N. Due to the load applied, the hair fiber stretches and elongates approximately $2.0 \%$ of its initial length (elastic property). Next, the fiber stretches rapidly about 25.0 to $30.0 \%$ of the length, as a result of moderate load increase (plastics property). Thus, if the applied force is a constant value, the fiber stretches in proportion to the load until the fracture occurs (Velasco et al., 2009; Woodruff, 2002). The lower values related to breaking strength represent more damaged cortex.

\section{Color changes}

The perception of color is very subjective, and, therefore, it is important to use analytical methods to allow discrete measurements to be taken. One model existing to measure color is developed and proposed in 1976 by Commision Internationale L'Eclairage, CIELAB or CIE L* a* b*. Such model measures color on three main axes clearly linear human perception (Gulrajani, 2010). Standard $\mathbf{L}^{*}, \mathbf{a}^{*}, \mathbf{b}^{*}$ measurements were collected where $\mathbf{L}^{*}$ that represents the brightness (with positive values standing for clearer and negative values meaning darker), $\mathbf{a}^{*}$ defines the color-coordinated green-red (being positive if the hair shows shades of red and negative for shades 
of green), $\mathbf{b}^{*}$ defines the color-coordinated blue-yellow (with shades of yellow presented by positive numbers and shades of blue by negative) (Dario et al., 2013; Gulrajani, 2010; Nogueira et al., 2004).

Color measurements were performed by the Hunter Miniscan Labs ${ }^{\mathrm{TM}}$ XE Plus (CIELAB - Universal Software v. 4.01) using the middle portion regions of the tresses and five replicates. Hunter L-a-b parameters were measured. The equipment provides the color parameters based on three vectors: $\mathbf{L}^{*}$, $\mathbf{a}^{*}$ and $\mathbf{b}$ * (Dario et al., 2013; Nogueira et al., 2004).

\section{Statistical analysis}

Possible significant differences in the results were analyzed by one-way ANOVA and the differences between treatments were identified by Tukey's test $(\alpha=0.05)$.

\section{RESULTS AND DISCUSSION}

\section{Physical-chemical and organoleptic changes in emulsion and gel-based hair dye formulations}

Changes in consistency and appearance of the formulations after addition of pigments and ammonium hydroxide are described at Table I and II. The Light blond dye provided light purple color to the emulsions (LAN, CRO, POL, and COS); slightly yellow for most gels (CAR, ARI, and AMI), and a brownish color to the NAT-base. This can be explained by the reaction between precursor ( $p$-aminophenol) and couplers (resorcinol and 4-amino-2-hydroxytoluene) presented on the light blond dye. When these components react, a light purple color is developed. However, when no reaction occurs, no purple but slightly yellow to brown color is achieved, as seen in our gel dyes (Brown, Corbett, 1979; Corbett, 1984). Meanwhile, the Light brown dye provided a brownish color to the emulsions (LAN, CRO, POL, and COS) and to the NAT-base gel and a slightly yellowish color to the others gel formulations (CAR, ARI, and AMI). Again, this color was developed due to the reaction between precursor ( $p$-phenylenediamine) and couplers ( $m$-aminophenol, resorcinol, and 2,4-diaminophenoxyethanol), resulting in a slightly yellow to brownish color, depending of oxidative reaction (Corbett, 1973; Corbett, 1984).

Besides color characteristics, Tables I and II show physical-chemical characteristics ( $\mathrm{pH}$ and viscosity) for emulsion and gel dye formulations. All formulations presented $\mathrm{pH}$ range between 10.2 and 11.2, expected values for hair dyes. According to Corbett (1984), highly alkaline formulations ( $\mathrm{pH}$ range $9.0-12.0$ ) open the cuticle cells, allowing penetration of the oxidative dye into the hair cortex. There, the compounds react, forming a pigment with high molar mass (Shansky, 2007). Moreover, the hair dye viscosity should be controlled, because it can affect the product handling and efficacy: the formulation should adhere to the hair surface, but also does not drip on your clothes. All formulations showed a viscosity between 400 and 4,000 $\mathrm{mPa} \cdot \mathrm{s}^{-1}$, in line with expected values (Hoch et al., 1985).

\section{Breaking strength}

Figures 1-4 show the breaking strength data for virgin Caucasian hair samples (light blond or dark brown hair), without $(\mathrm{VH})$ or with treatment with oxidative hair

TABLE I - Physic-chemical and organoleptic characteristics of different hair dye color emulsions types

\begin{tabular}{|c|c|c|c|c|}
\hline \multirow{2}{*}{ Emulsion type } & \multirow{2}{*}{ Hair dye color } & \multicolumn{3}{|c|}{ Evaluated Characteristics } \\
\hline & & Organoleptic (color) & pH & Viscosity $\left(\mathrm{mPa}^{-1} \mathrm{~s}^{-1}\right.$ \\
\hline LAN & Light blond & light purple color & $11.07 \pm 0.07$ & $2,200 \pm 80.13$ \\
\hline LAN & Light brown & brownish color & $10.46 \pm 0.01$ & $1,900 \pm 102.32$ \\
\hline CRO & Light blond & light purple color & $11.20 \pm 0.01$ & $2,000 \pm 66.09$ \\
\hline CRO & Light brown & brownish color & $10.40 \pm 0.01$ & $2,800 \pm 87.60$ \\
\hline POL & Light blond & light purple color & $10.88 \pm 0.01$ & $1,800 \pm 106.06$ \\
\hline POL & Light brown & brownish color & $10.71 \pm 0.09$ & $2,900 \pm 47.16$ \\
\hline $\cos$ & Light blond & light purple color & $11.18 \pm 0.01$ & $3,200 \pm 55.47$ \\
\hline $\mathrm{COS}$ & Light brown & brownish color & $10.55 \pm 0.01$ & $2,900 \pm 85.33$ \\
\hline
\end{tabular}

Legend: CRO: Cetearyl Alcohol (and) Dicetyl Phosphate (and) Ceteth-10 Phosphate/Crodafos ${ }^{\mathrm{TM}}$ CES; LAN: Cetearyl Alcohol (and) Sodium Lauryl Sulfate (and) Sodium Cetearyl Sulfate/ Lanette N ${ }^{\mathrm{TM}}$; COS: Cetearyl Alcohol (and) Ceteareth-20/Cosmowax J ${ }^{\mathrm{TM}}$; POL: Cetearyl Alcohol (and) Polysorbate 60/ Polawax NF ${ }^{\mathrm{TM}}$ 
Influence of different cosmetic vehicles in mechanical and physical properties of hair treated with oxidative hair dyes

TABLE II - Physic-chemical and organoleptic characteristics of different hair dye color gels types

\begin{tabular}{|c|c|c|c|c|}
\hline \multirow{2}{*}{ Gel type } & \multirow{2}{*}{ Hair dye color } & \multicolumn{3}{|c|}{ Evaluated Characteristics } \\
\hline & & Organoleptic (color) & pH & Viscosity $\left(\mathrm{mPa}^{-1}\right)$ \\
\hline CAR & Light blond & slightly yellow & $10.57 \pm 0.01$ & $2,530 \pm 49.33$ \\
\hline CAR & Light brown & slightly yellow & $10.26 \pm 0.03$ & $2,060 \pm 43.66$ \\
\hline ARI & Light blond & slightly yellow & $10.51 \pm 0.02$ & $1,820 \pm 60,00$ \\
\hline ARI & Light brown & slightly yellow & $10.47 \pm 0.01$ & $2,290 \pm 30.35$ \\
\hline AMI & Light blond & slightly yellow & $10.88 \pm 0.01$ & $1,600 \pm 88.00$ \\
\hline AMI & Light brown & slightly yellow & $10.38 \pm 0.04$ & $1,680 \pm 37.16$ \\
\hline NAT & Light blond & brownish color & $10.80 \pm 0.03$ & $1,750 \pm 18.00$ \\
\hline NAT & Light brown & brownish color & $10.40 \pm 0.02$ & $1,800 \pm 33.85$ \\
\hline
\end{tabular}

Legend: ARI: Ammonium Acryloyldimethyltaurate (and) VP Copolymer/ Aristoflex avc ${ }^{\mathrm{TM}}$; CAR: Carbomer/Carbopol ${ }^{\mathrm{TM}} 980$; NAT: Hydroxyethylcellulose Natrosol $^{\mathrm{TM}}$; AMI: Sclerotium gum/Amigel ${ }^{\mathrm{TM}}$

dye (light brown or light blond color) in different vehicles (CRO, LAN, COS, POL, ARI, CAR, NAT, and AMI). Figure 1 represents Group I Caucasian dark brown virgin hair and samples treated with light brown oxidative hair dyes, Figure 2 represents Group II Caucasian dark brown virgin hair and samples treated with light blond oxidative hair dyes. Figure 3 represents Group III Caucasian light blond virgin hair and samples treated light brown oxidative hair dyes. Figure 4 represents Group IV Caucasian light blond virgin hair and samples treated with light blond oxidative hair dyes. The results demonstrated there was no statistical difference among all treatments.

Our study contradicts the findings presented by Nogueira, Nakano, Joekes (2004), in which the oxidative process (bleaching) changed in the breaking strength value. Although Robbins, Crawford (1991) confirmed that hair dye damages the cuticle layer, there was no traceable change while measuring tensile properties.

\section{Color changes}

Tables III-VI show the Color and Brightness parameters data for virgin Caucasian hair samples (light blond or dark brown hair), without (VH) or with treatment with oxidative hair dye light or brown color in vehicles different.

According to the results of Table III, in relation to the brightness parameter $\left(\mathbf{L}^{*}\right)$ from dark brown hair treated

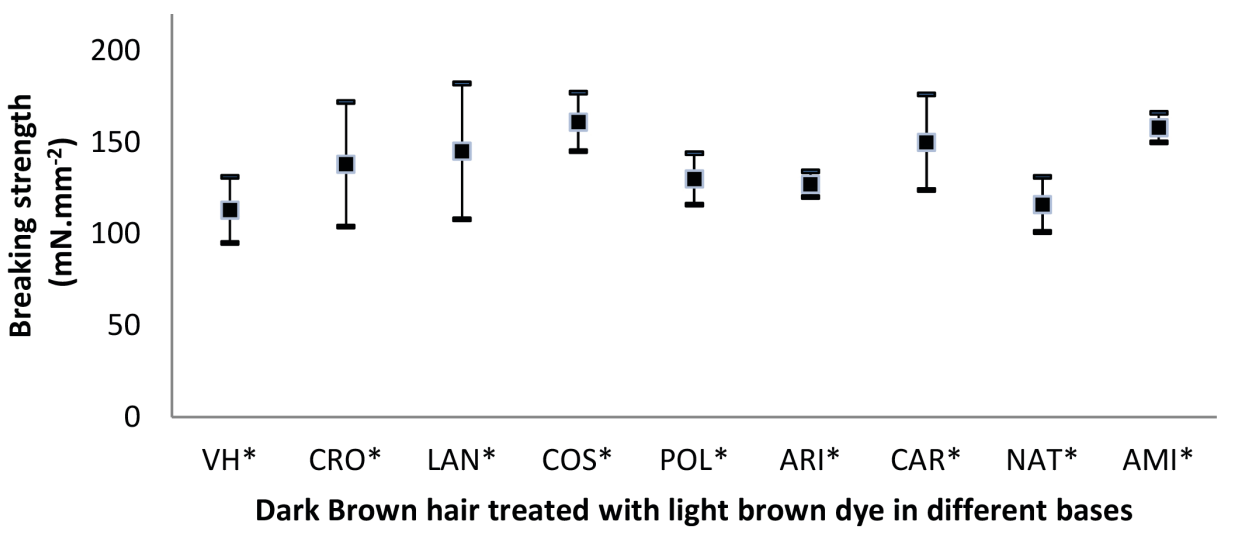

FIGURE 1 - Breaking strength for Caucasian dark brown virgin hair and samples treated with light brown oxidative hair dyes. Results categorized with equal symbols $\left({ }^{*}\right)$ mean the data didn't present as statistically and significantly different for $\alpha=5, \mathrm{p}<0.05, \mathrm{n}=5$. VH: Virgin Hair; CRO: Cetearyl Alcohol (and) Dicetyl Phosphate (and) Ceteth-10 Phosphate/Crodafos ${ }^{\mathrm{TM}}$ CES; LAN: Cetearyl Alcohol (and) Sodium Lauryl Sulfate (and) Sodium Cetearyl Sulfatel Lanette N ${ }^{\mathrm{TM}}$; COS: Cetearyl Alcohol (and) Ceteareth-20/ Cosmowax JM. POL: Cetearyl Alcohol (and) Polysorbate 60/Polawax NF ${ }^{\mathrm{TM}}$; ARI: Ammonium Acryloyldimethyltaurate (and) VP Copolymer/Aristoflex avc ${ }^{\mathrm{TM}}$; CAR: Carbomer/Carbopol ${ }^{\mathrm{TM}}$ 980; NAT: Hydroxyethylcellulose/Natrosol ${ }^{\mathrm{TM}} \mathrm{HHR}$; AMI: Sclerotium gum/ Amigel ${ }^{\mathrm{TM}}$. 


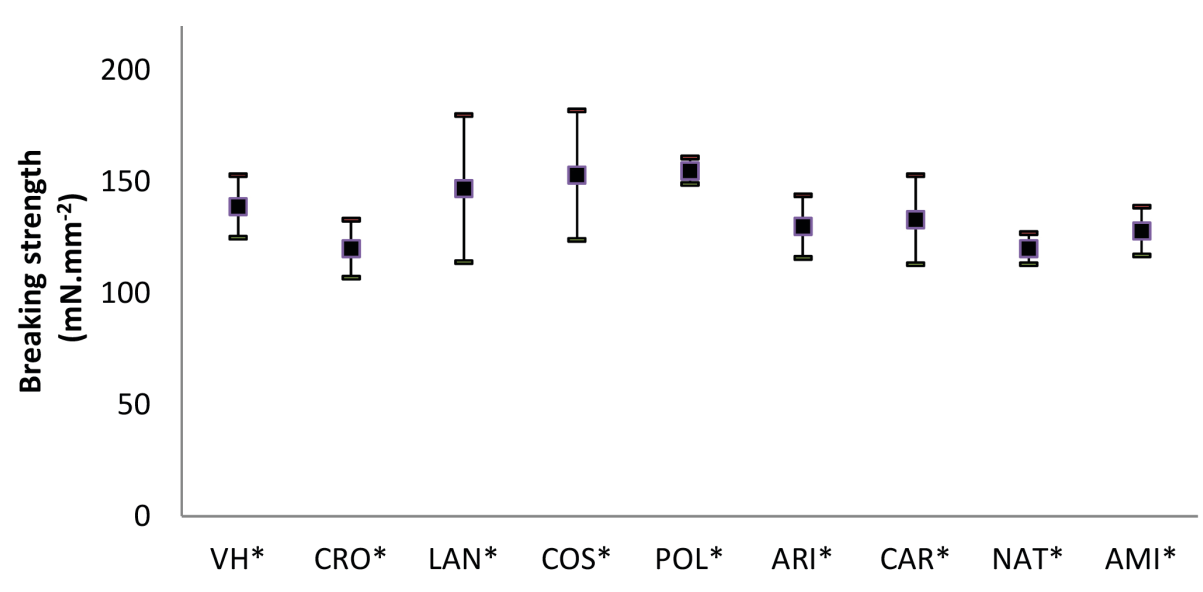

Light blond hair treated with light brown dye in different bases

FIGURE 2 - Breaking strength for Caucasian dark brown virgin hair and samples treated with light blond oxidative hair dyes. Results categorized with equal symbols $(*)$ mean they didn't present as statistically and significantly different, for $\alpha=5, \mathrm{p}<0.05, \mathrm{n}=5$. VH: Virgin Hair; CRO: Cetearyl Alcohol (and) Dicetyl Phosphate (and) Ceteth-10 Phosphate/Crodafos ${ }^{\mathrm{TM}}$ CES; LAN: Cetearyl Alcohol (and) Sodium Lauryl Sulfate (and) Sodium Cetearyl Sulfate/Lanette N ${ }^{\mathrm{TM}}$; COS: Cetearyl Alcohol (and) Ceteareth-20/ Cosmowax JT, POL: Cetearyl Alcohol (and) Polysorbate 60/Polawax NF ${ }^{\mathrm{TM}}$; ARI: Ammonium Acryloyldimethyltaurate (and) VP Copolymer/Aristoflex avc ${ }^{\mathrm{TM}}$; CAR: Carbomer/Carbopol ${ }^{\mathrm{TM}}$ 980; NAT: Hydroxyethylcellulose/Natrosol ${ }^{\mathrm{TM}} \mathrm{HHR}$; AMI: Sclerotium gum/Amigel ${ }^{\mathrm{TM}}$.

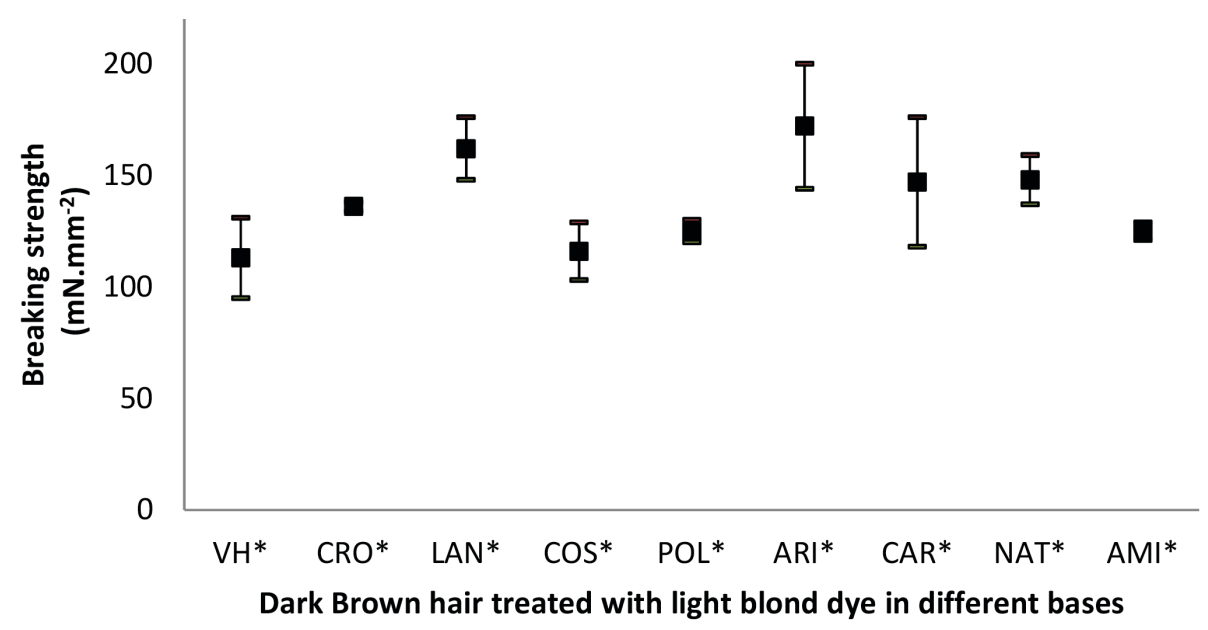

FIGURE 3 - Breaking strength for Caucasian light blond virgin hair and samples treated with light brown oxidative hair dyes. Results categorized with equal symbols $(*)$ mean they didn't present as statistically and significantly different, for $\alpha=5, \mathrm{p}<0.05, \mathrm{n}=5$. VH: Virgin Hair; CRO: Cetearyl Alcohol (and) Dicetyl Phosphate (and) Ceteth-10 Phosphate/Crodafos ${ }^{\mathrm{TM}}$ CES; LAN: Cetearyl Alcohol (and) Sodium Lauryl Sulfate (and) Sodium Cetearyl Sulfate/ Lanette N ${ }^{\mathrm{TM}}$; COS: Cetearyl Alcohol (and) Ceteareth-20/ Cosmowax J ${ }^{\mathrm{TM}}$; POL: Cetearyl Alcohol (and) Polysorbate 60/Polawax NF ${ }^{\mathrm{TM}}$; ARI: Ammonium Acryloyldimethyltaurate (and) VP Copolymer/Aristoflex avc ${ }^{\mathrm{TM}}$; CAR: Carbomer/Carbopol ${ }^{\mathrm{TM}}$ 980; NAT: Hydroxyethylcellulose/Natrosol ${ }^{\mathrm{TM}} \mathrm{HHR}$; AMI: Sclerotium gum/Amigel ${ }^{\mathrm{TM}}$.

with light brown dye, it is possible to infer that light brown dyes formulated with emulsions CRO, COS, and, POL presented statistically significant increase in luminosity values. In relation to virgin hair tress, among the gels dyes formulations, CAR and AMI showed the same result. That said, regarding to red-green color parameter $\left(\mathbf{a}^{*}\right)$, emulsion and gels dye formulations revealed increased negative values. In other words, it is statistically higher red color intensity when compared to virgin hair samples. All the samples showed positive values in the coordinate yellow-blue color $\left(\mathbf{b}^{*}\right)$, that means yellow color values. When compared with virgin hair, all treated samples revealed statistically decrease in yellow-color intensity.

In conformity with the results showed in Table IV, in relation to the brightness parameter $\left(\mathbf{L}^{*}\right)$ from dark brown hair treated with light blond dye, there was a statically 


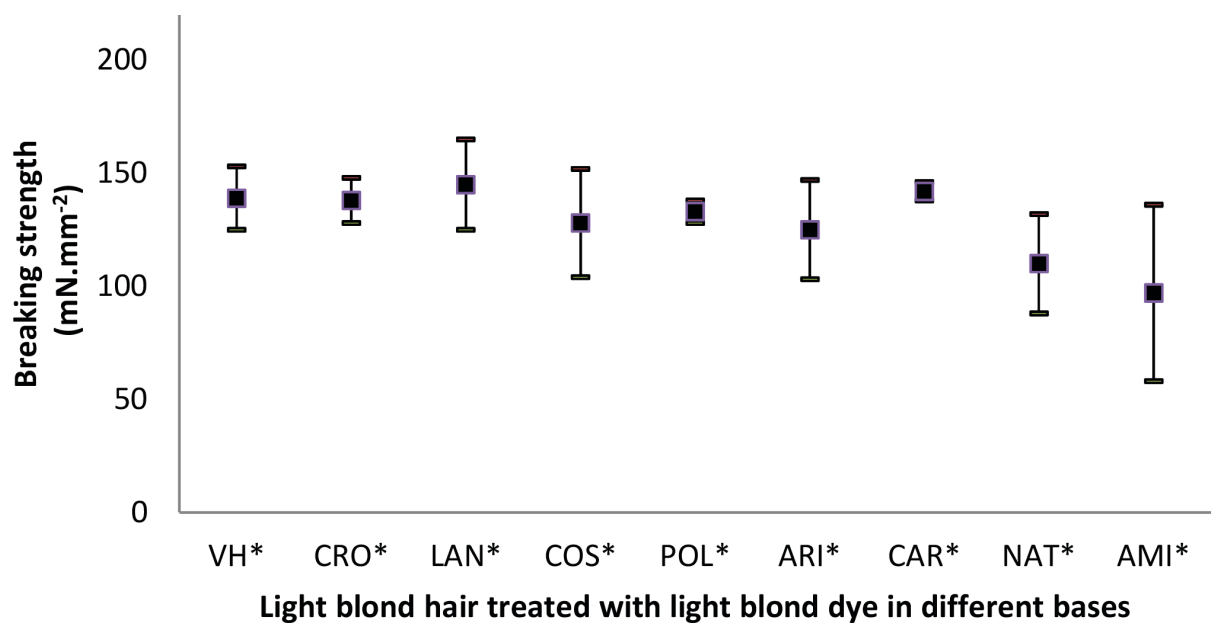

FIGURE 4 - Breaking strength for Caucasian light blond virgin hair and samples treated with light blond oxidative hair dyes. Results categorized with equal symbols (*) didn't present as statistically and significantly different, for $\alpha=5, \mathrm{p}<0.05, \mathrm{n}=5$. VH: Virgin Hair; CRO: Cetearyl Alcohol (and) Dicetyl Phosphate (and) Ceteth-10 Phosphate/Crodafos ${ }^{\mathrm{TM}}$ CES; LAN: Cetearyl Alcohol (and) Sodium Lauryl Sulfate (and) Sodium Cetearyl Sulfate/Lanette N ${ }^{\mathrm{TM}}$; COS: Cetearyl Alcohol (and) Ceteareth-20/ Cosmowax JM- POL: Cetearyl Alcohol (and) Polysorbate 60/Polawax NF ${ }^{\mathrm{TM}}$; ARI: Ammonium Acryloyldimethyltaurate (and) VP Copolymer/Aristoflex avc ${ }^{\mathrm{TM}}$; CAR: Carbomer/Carbopol ${ }^{\mathrm{TM}}$ 980; NAT: Hydroxyethylcellulose/Natrosol ${ }^{\mathrm{TM}} \mathrm{HHR}$; AMI: Sclerotium gum/Amigel ${ }^{\mathrm{TM}}$.

TABLE III - Color and Brightness parameter for Caucasian dark brown virgin hair and samples treated with light brown oxidative hair dyes

\begin{tabular}{lccc}
\hline $\begin{array}{l}\text { Treatment } \\
\text { hair dye color }\end{array}$ & \multicolumn{3}{c}{ Dark brown hair } \\
\hline Light brown & $\mathbf{L}^{*}$ & $\mathbf{a}^{*}$ & $\mathbf{b}^{*}$ \\
\hline$V H$ & $15.15 \pm 0.32^{\mathrm{c}}$ & $-0.48 \pm 0.13^{\mathrm{a}}$ & $5.39 \pm 0.19^{\mathrm{a}}$ \\
$C R O$ & $16.37 \pm 0.49^{\mathrm{a}}$ & $-1.42 \pm 0.11^{\mathrm{b}, \mathrm{c}}$ & $4.78 \pm 0.22^{\mathrm{b}}$ \\
$L A N$ & $15.56 \pm 0.18^{\mathrm{b}, \mathrm{c}}$ & $-1.14 \pm 0.34^{\mathrm{b}}$ & $4.60 \pm 0.15^{\mathrm{b}, \mathrm{c}}$ \\
$C O S$ & $16.76 \pm 0.11^{\mathrm{a}}$ & $-1.46 \pm 0.17^{\mathrm{b}, \mathrm{c}}$ & $4.65 \pm 0.21^{\mathrm{b}, \mathrm{c}}$ \\
$P O L$ & $16.42 \pm 0.11^{\mathrm{a}}$ & $-1.37 \pm 0.12^{\mathrm{b}, \mathrm{c}}$ & $4.55 \pm 0.19^{\mathrm{b}, \mathrm{c}}$ \\
$A R I$ & $15.45 \pm 0.19^{\mathrm{c}}$ & $-1.64 \pm 0.07^{\mathrm{c}}$ & $4.14 \pm 0.23^{\mathrm{c}}$ \\
$C A R$ & $16.20 \pm 0.19^{\mathrm{a}}$ & $-1.35 \pm 0.16^{\mathrm{b}, \mathrm{c}}$ & $4.47 \pm 0.12^{\mathrm{b}, \mathrm{c}}$ \\
$N A T$ & $15.26 \pm 0.07^{\mathrm{c}}$ & $-1.49 \pm 0.14^{\mathrm{b}, \mathrm{c}}$ & $4.67 \pm 0.23^{\mathrm{b}, \mathrm{c}}$ \\
$A M I$ & $16.27 \pm 0.15^{\mathrm{a}}$ & $-1.82 \pm 0.10^{\mathrm{c}}$ & $4.31 \pm 0.12^{\mathrm{b}, \mathrm{c}}$ \\
\hline
\end{tabular}

Results categorized with different letters presents as statistically and significantly different for $\alpha=5, p<0.05, n=5$. $L^{*}$ : brightness parameter; $a^{*}$ : parameter of color in the red-green coordinate; $\mathrm{b}^{*}$ : parameter color of yellow-blue coordinate. VH: Virgin Hair; CRO: Cetearyl Alcohol (and) Dicetyl Phosphate (and) Ceteth-10 Phosphate/Crodafos ${ }^{\mathrm{TM}}$ CES; LAN: Cetearyl Alcohol (and) Sodium Lauryl Sulfate (and) Sodium Cetearyl Sulfatel Lanette N ${ }^{\mathrm{TM}}$; COS: Cetearyl Alcohol (and) Ceteareth-20/ Cosmowax J ${ }^{\mathrm{TM}}$; POL: Cetearyl Alcohol (and) Polysorbate 60/ Polawax NF ${ }^{\mathrm{TM}}$;ARI: Ammonium Acryloyldimethyltaurate (and) VP Copolymer/Aristoflex avc ${ }^{\mathrm{TM}}$; CAR: Carbomer/Carbopol ${ }^{\mathrm{TM}}$ 980; NAT: Hydroxyethylcellulose Natrosol $^{\mathrm{TM}}$; AMI: Sclerotium gum/Amigel ${ }^{\mathrm{TM}}$.
TABLE IV - Color and Brightness parameter for Caucasian dark brown virgin hair and samples treated with light blond oxidative hair dyes

\begin{tabular}{lccc}
\hline $\begin{array}{l}\text { Treatment } \\
\text { hair dye color }\end{array}$ & \multicolumn{3}{c}{ Dark brown hair } \\
\hline Light blond & $\mathbf{L}^{*}$ & $\mathbf{a}^{*}$ & $\mathbf{b}^{*}$ \\
\hline$V H$ & $15.15 \pm 0.32^{\mathrm{e}}$ & $-0.48 \pm 0.13^{\mathrm{f}}$ & $5.39 \pm 0.19^{\mathrm{e}}$ \\
$C R O$ & $19.93 \pm 0.13^{\mathrm{b}, \mathrm{c}}$ & $3.96 \pm 0.37^{\mathrm{c}}$ & $9.59 \pm 0.43^{\mathrm{c}}$ \\
$L A N$ & $18.77 \pm 0.52^{\mathrm{d}}$ & $3.67 \pm 0.03^{\mathrm{c}, \mathrm{d}}$ & $9.95 \pm 0.09^{\mathrm{b}, \mathrm{c}}$ \\
$C O S$ & $20.51 \pm 0.13^{\mathrm{a}, \mathrm{b}}$ & $4.02 \pm 0.10^{\mathrm{c}}$ & $9.68 \pm 0.38^{\mathrm{c}}$ \\
$P O L$ & $19.98 \pm 0.15^{\mathrm{b}, \mathrm{c}}$ & $3.89 \pm 0.14^{\mathrm{c}}$ & $9.77 \pm 0.27^{\mathrm{b}, \mathrm{c}}$ \\
$A R I$ & $18.88 \pm 0.16^{\mathrm{d}}$ & $2.79 \pm 0.10^{\mathrm{e}}$ & $8.68 \pm 0.27^{\mathrm{d}}$ \\
$C A R$ & $18.55 \pm 0.11^{\mathrm{d}}$ & $3.22 \pm 0.13^{\mathrm{e}}$ & $8.31 \pm 0.19^{\mathrm{d}}$ \\
$N A T$ & $19.59 \pm 0.07^{\mathrm{c}}$ & $4.56 \pm 0.13^{\mathrm{b}}$ & $10.52 \pm 0.27^{\mathrm{b}}$ \\
$A M I$ & $20.68 \pm 0.11^{\mathrm{a}}$ & $5.92 \pm 0.07^{\mathrm{a}}$ & $11.69 \pm 0.25^{\mathrm{a}}$ \\
\hline
\end{tabular}

Results categorized with different letters presents as statistically and significantly different for $\alpha=5, \mathrm{p}<0.05, \mathrm{n}=5$. $\mathrm{L}^{*}$ : brightness parameter; $a^{*}$ : parameter of color in the red-green coordinate; $\mathrm{b}^{*}$ : parameter color of yellow-blue coordinate. VH: Virgin Hair; CRO: Cetearyl Alcohol (and) Dicetyl Phosphate (and) Ceteth-10 Phosphate/Crodafos ${ }^{\mathrm{TM}}$ CES; LAN: Cetearyl Alcohol (and) Sodium Lauryl Sulfate (and) Sodium Cetearyl Sulfatel Lanette N ${ }^{\mathrm{TM}}$; COS: Cetearyl Alcohol (and) Ceteareth-20/ Cosmowax J ${ }^{\mathrm{TM}}$; POL: Cetearyl Alcohol (and) Polysorbate 60/ Polawax NF ${ }^{\mathrm{TM}}$; ARI: Ammonium Acryloyldimethyltaurate (and) VP Copolymer/Aristoflex avc ${ }^{\mathrm{TM}}$; CAR: Carbomer/Carbopol ${ }^{\mathrm{TM}}$ 980; NAT: Hydroxyethylcellulose Natrosol $^{\mathrm{TM}}$; AMI: Sclerotium

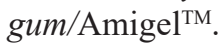


TABLE V - Color and Brightness parameter for Caucasian light blond virgin hair and samples treated with light brown oxidative hair dyes

\begin{tabular}{lccc}
\hline $\begin{array}{l}\text { Treatment } \\
\text { hair dye color }\end{array}$ & \multicolumn{3}{c}{ Light Blond hair } \\
\hline Light brown & $\mathbf{L}^{*}$ & $\mathbf{a}^{*}$ & $\mathbf{b}^{*}$ \\
\hline$V H$ & $68.04 \pm 0.19^{\mathrm{a}}$ & $5.80 \pm 0.33^{\mathrm{a}}$ & $37.02 \pm 0.36^{\mathrm{a}}$ \\
$C R O$ & $16.50 \pm 0.19^{\mathrm{c}, \mathrm{d}}$ & $-0.72 \pm 0.15^{\mathrm{b}}$ & $5.89 \pm 0.37^{\mathrm{b}}$ \\
$L A N$ & $17.39 \pm 0.10^{\mathrm{b}}$ & $-0.98 \pm 0.16^{\mathrm{b}}$ & $5.13 \pm 0.08^{\mathrm{b}}$ \\
$C O S$ & $16.00 \pm 0.13^{\mathrm{d}, \mathrm{e}}$ & $-0.93 \pm 0.15^{\mathrm{b}}$ & $5.40 \pm 0.29^{\mathrm{b}}$ \\
$P O L$ & $16.21 \pm 0.13^{\mathrm{c}, \mathrm{d}}$ & $-0.95 \pm 0.17^{\mathrm{b}}$ & $5.45 \pm 0.18^{\mathrm{b}}$ \\
$A R I$ & $17.50 \pm 0.07^{\mathrm{b}}$ & $-0.86 \pm 0.06^{\mathrm{b}}$ & $5.74 \pm 0.09^{\mathrm{b}}$ \\
$C A R$ & $15.50 \pm 0.32^{\mathrm{e}}$ & $-0.70 \pm 0.21^{\mathrm{b}}$ & $5.66 \pm 0.40^{\mathrm{b}}$ \\
$N A T$ & $16.30 \pm 0.32^{\mathrm{c}, \mathrm{d}}$ & $-0.80 \pm 0.20^{\mathrm{b}}$ & $5.23 \pm 0.25^{\mathrm{b}}$ \\
$A M I$ & $16.72 \pm 0.20^{\mathrm{c}}$ & $-0.70 \pm 0.10^{\mathrm{b}}$ & $5.80 \pm 0.27^{\mathrm{b}}$ \\
\hline
\end{tabular}

Results categorized with different letters presents as statistically and significantly different for $\alpha=5, p<0.05, n=5$. $L^{*}$ : brightness parameter; $\mathrm{a}^{*}$ : parameter of color in the red-green coordinate; $\mathrm{b}^{*}$ : parameter color of yellow-blue coordinate. VH: Virgin Hair; CRO: Cetearyl Alcohol (and) Dicetyl Phosphate (and) Ceteth-10 Phosphate/Crodafos ${ }^{\mathrm{TM}}$ CES; LAN: Cetearyl Alcohol (and) Sodium Lauryl Sulfate (and) Sodium Cetearyl Sulfatel Lanette N ${ }^{\mathrm{TM}}$; COS: Cetearyl Alcohol (and) Ceteareth-20/ Cosmowax J ${ }^{\mathrm{TM}}$; POL: Cetearyl Alcohol (and) Polysorbate 60/ Polawax NF ${ }^{\mathrm{TM}}$; ARI: Ammonium Acryloyldimethyltaurate (and) VP Copolymer/Aristoflex avc ${ }^{\mathrm{TM}}$; CAR: Carbomer/Carbopol ${ }^{\mathrm{TM}}$ 980; NAT: Hydroxyethylcellulose Natrosol $^{\mathrm{TM}}$; AMI: Sclerotium gum/Amigel ${ }^{\mathrm{TM}}$.

increase of brightness in all samples. Hair treated with COS and AMI showed as non-statically different among each other and they represent the highest values achieved. All samples presented a statistic increase in the red-green color parameter $\left(\mathbf{a}^{*}\right)$ changing from red color (negative) in the virgin hair tresses to green (positive) values in dyed tresses. The treated hair also showed a statistic increase in coordinating the yellow-blue color $\left(\mathbf{b}^{*}\right)$.

Light blond hair treated with light brown dye presented (Table V) that the brightness parameter $\left(\mathbf{L}^{*}\right)$ decreased in all samples, when compared with the virgin hair. The greater decrease was observed with COS and CAR. When considering the red-green color parameter $\left(\mathbf{a}^{*}\right)$, the virgin hair showed positive value, which means green in the coordinate. Also, in this matter, all treated samples presented negatives values (red color) and there are no statistic differences among them. All treated samples also revealed yellow-blue parameter ( $\left.\mathbf{b}^{*}\right)$, which decreased when compared to the non-treated hair. However, it presented no statistic differences among them.
TABLE VI - Color and Brightness parameter for Caucasian light blond virgin hair and samples treated with light blond oxidative hair dyes

\begin{tabular}{lccc}
\hline $\begin{array}{l}\text { Treatment } \\
\text { hair dye color }\end{array}$ & \multicolumn{3}{c}{ Light Blond hair } \\
\hline Light blond & $\mathbf{L}^{*}$ & $\mathbf{a}^{*}$ & $\mathbf{b}^{*}$ \\
\hline$V H$ & $68.04 \pm 0.19^{\mathrm{a}}$ & $5.80 \pm 0.33^{\mathrm{f}}$ & $37.02 \pm 0.36^{\mathrm{e}}$ \\
$C R O$ & $61.51 \pm 0.19^{\mathrm{b}}$ & $12.96 \pm 0.18^{\mathrm{e}}$ & $35.69 \pm 0.37^{\mathrm{e}}$ \\
$L A N$ & $61.68 \pm 0.02^{\mathrm{b}}$ & $13.24 \pm 0.04^{\mathrm{e}}$ & $35.88 \pm 0.07^{\mathrm{e}}$ \\
$C O S$ & $59.60 \pm 0.93^{\mathrm{c}}$ & $17.04 \pm 0.67^{\mathrm{d}}$ & $36.58 \pm 1.25^{\mathrm{d}, \mathrm{e}}$ \\
$P O L$ & $59.85 \pm 0.10^{\mathrm{b}, \mathrm{c}}$ & $16.54 \pm 0.42^{\mathrm{d}}$ & $36.98 \pm 0.22^{\mathrm{d}, \mathrm{e}}$ \\
$A R I$ & $58.98 \pm 0.03^{\mathrm{c}}$ & $19.98 \pm 0.01^{\mathrm{c}}$ & $37.76 \pm 0.05^{\mathrm{c}, \mathrm{d}}$ \\
$C A R$ & $49.75 \pm 0.81^{\mathrm{e}}$ & $22.82 \pm 0.60^{\mathrm{b}}$ & $38.66 \pm 0.81^{\mathrm{b}, \mathrm{c}}$ \\
$N A T$ & $54.00 \pm 0.75^{\mathrm{d}}$ & $25.45 \pm 0.11^{\mathrm{a}}$ & $42.35 \pm 0.12^{\mathrm{a}}$ \\
$A M I$ & $55.15 \pm 1.34^{\mathrm{d}}$ & $22.28 \pm 0.65^{\mathrm{b}}$ & $40.05 \pm 0.22^{\mathrm{b}}$ \\
\hline
\end{tabular}

Results categorized with different letters presents as statistically and significantly different, for $\alpha=5, p<0.05, n=5$. $L^{*}$ : brightness parameter; $\mathrm{a}^{*}$ : parameter of color in the red-green coordinate; $b^{*}$ : parameter color of yellow-blue coordinate. VH: Virgin Hair; CRO: Cetearyl Alcohol (and) Dicetyl Phosphate (and) Ceteth-10 Phosphate/Crodafos ${ }^{\mathrm{TM}}$ CES; LAN: Cetearyl Alcohol (and) Sodium Lauryl Sulfate (and) Sodium Cetearyl Sulfate/ Lanette N ${ }^{\mathrm{TM}}$; COS: Cetearyl Alcohol (and) Ceteareth-20/Cosmowax J ${ }^{\mathrm{TM}}$; POL: Cetearyl Alcohol (and) Polysorbate 60/Polawax NF ${ }^{\mathrm{TM}}$; ARI: Ammonium Acryloyldimethyltaurate (and) VP Copolymer/Aristoflex avc ${ }^{\mathrm{TM}}$; CAR: Carbomer/Carbopol ${ }^{\mathrm{TM}}$ 980; NAT: Hydroxyethylcellulose Natrosol $^{\mathrm{TM}}$; AMI: Sclerotium gum/Amigel ${ }^{\mathrm{TM}}$.

Considering the brightness parameter $\left(\mathbf{L}^{*}\right)$ from light blond hair treated with light blond dye (Table VI), a brightness decrease was observed when compared to the virgin hair. Regarding to red-green color parameter $\left(\mathbf{a}^{*}\right)$, all samples revealed red-color intensity increase when compared to the hair without treatment (virgin) and the highest increase was observed among the gels formulations. When considering the yellow-blue color $\left(\mathbf{b}^{*}\right)$ parameter, there was no statistic difference between virgin hair and samples treated with emulsion based formulations. However, samples treated with any gel formulation presented an increase in these parameters, which led to a higher yellow color intensity.

Considering the results presented in Table III-VI, concerning hair brightness and color changes after a dyeing process, it was observed that the cosmetic vehicle and, also, the hair type which the formulation is applied on can influence data related to this parameter.

These results can be explained by chemical compounds found in hair dyes. According Gama et al. 
(2009) the final color of a hair dye is obtained after the reaction between the precursor and the couplers in a strong alkaline and oxidant medium. In this study, the alkalinizing agent applied was ammonium hydroxide. It is important to stress that, according to the same study carried out by Gama et al. (2009), the light brown dye had a lower percentage of ammonium hydroxide than the light blond dye and this fact is confirmed by the results of Table I and II, where the $\mathrm{pH}$ values were slightly higher for light blond dye than light brown dye.

The high percentage of ammonium hydroxide in the light blond dye and the presence of the precursor ( $p$-aminophenol) and couplers (resorcinol and 4-amino2-hydroxytoluene) causes them to react and it occurs the development of light purple color, but when it isn't completed the final color is slightly yellow to brown color (Brown, Corbett, 1979; Corbett, 1984). These could explain the increased positive values for Brightness $\left(\mathbf{L}^{*}\right)$; red-green color $\left(\mathbf{a}^{*}\right)$ and yellow-blue color $\left(\mathbf{b}^{*}\right)$ for virgin dark brown hair, after all treatments with this hair dye (Table IV), possibly by oxidation of melanin. Meanwhile, for virgin light blond hair the results after treatments (Table VI) were negatives values for $\mathbf{L}^{*}$; positives value for $\mathbf{a}^{*}$ and the most varied results for $\mathbf{b}^{*}$.

When we analyzed the results of hair color of the light brown dye (Table III and V) as previously mentioned, this product was composed of precursor ( $p$-phenylenediamine) and couplers ( $m$-aminophenol; resorcinol and 2,4-diaminophenoxyethanol) and the result of reaction of them was the brownish color (Corbett, 1973; Corbett, 1984), that could explain the increased negative values for Brightness $\left(\mathbf{L}^{*}\right)$; red-green color $\left(\mathbf{a}^{*}\right)$ and yellowblue color $\left(\mathbf{b}^{*}\right)$ for virgin dark brown hair, and also for virgin light blond hair after all treatments with this hair dye.

The results presented (Table III and V) for gel formulations provide color and brightness alterations in the same way as emulsion formulation, presenting similar differences between the two types of vehicles, in the Caucasian light blond hair or Caucasian light brown hair after treated with light brown oxidative hair dye. However, the Caucasian light blond hair or Caucasian light brown hair after treated with light blond oxidative hair dye, the results showed (Table IV and VI) that gel formulations provide color and brightness alteration in a different form that emulsion. For this part, a possible explanation considers that the gel formulation had a lower viscosity than emulsions (Table I and II). Also, the higher viscosity would contribute for more contact between the product and hair fiber. In addition, the modification degree in this parameter is better than among nonionic vehicles both in emulsion than in the gel.

\section{CONCLUSIONS}

During the coloring processing of hair, the dye formulations provide excessive cuticle opening, and it may cause, besides color change, modification in the parameters such as brightness and hair strength. Because of this, it is important to study the possible effects that may occur to the hair fiber, before to choose the formulation vehicle.

Regarding the resistance to breaking, an increasing tendency was observed in the breaking strength in treated hair tresses. However, the statistical treatment showed no significant differences between the tresses, indicating that the cuticle damage which allows oxidative dye penetration in the cortex did not affect the tensile human hair properties.

Concerning the hair brightness after a dyeing process, it was observed that not only the cosmetic vehicle but also the hair type influenced in this parameter. All dark brown virgin hair samples had brightness increase after the treatments with any formulation, whereas blond hair presented the opposite behavior. This behavior may be caused by different hair dyes composition and melanin types. In addition, the modification degree in this parameter was more noticeable among nonionic vehicles, in both emulsions (Polawax ${ }^{\mathrm{TM}}$, Cosmowax ${ }^{\mathrm{TM}}$ ) and gels vehicle (Natrosol ${ }^{\mathrm{TM}}$, Amigel $\left.{ }^{\mathrm{TM}}\right)$. The use of different cosmetic forms as a vehicle for hair dye increases the possibilities to use this kind of product, and, specifically, for the dark brown virgin hair, the results were similar for both the emulsion and gel.

\section{REFERENCES}

Alessandrini A, Piraccini BM. Essential of hair care cosmetics. Cosmetics. 2016;3(4):34.

Brasil. Agência Nacional de Vigilância Sanitária. Guia de controle de qualidade de produtos cosméticos. 2.ed. Brasília: Anvisa; 2008. p.27-32.

Brown KC, Corbett JF. The role of meta difunctional benzene derivates in oxidative hair dyeing. II. Reactions with p-aminophenols. J Soc Cosmet Chem. 1979;30(2):191-211.

Buchmann S. Main cosmetics vehicles. In: Barel AO, Paye M, Maibach HI. Handbook of cosmetic science and technology. New York: Informa Healthcare; 2001. p. 145-70.

Cai W, Gupta RB. Hydrogels. In: Kirk-Othmer. Chemical technology of cosmetics. New Jersey: John Wiley; 2012. p. 597-630. 
Corbett JF. Chemistry of hair colorant processes - science as an aid to formulation and development. J Soc Cosmet Chem. 1984;35(3):297-310.

Corbett JF. The role of meta difunctional benzene derivates in oxidative hair dyeing. II. Reactions with p-diamines. J Soc Cosmet Chem. 1973;24(2):103-34.

Dario MF, Pahl R, Castro JR, Lima FS, Kaneko TM, Pinto CASO, Baby AR, Velasco MVR. Efficacy of Punica granatum L. hydroalcoholic extract on properties of dyed hair exposed to UVA radiation. J Photochem Photobiol B: Biol. 2013;120(3):142-7.

França SA, Dario MF, Esteves VB, Baby AR, Velasco MVR. Types of hair dye and their mechanisms of action. Cosmetics. 2015;2:110-26.

Gama RM, Balogh TS, França S, Sá-Dias TC, Bedin V, Consiglieri VO, Kaneko TM, Baby AR, Velasco MVR. Evaluation of hair damage treated with oxidative hair dye under influence of conditioners agents. In: $26^{\text {th }}$ Congress IFSCC, 2010 , Buenos Aires. Book of abstracts: $26^{\text {th }}$ Congress IFSCC. Buenos Aires: AAQC, 2010. p. 378-9.

Gama RM, Balogh TS, França S, Sá-Dias TC, Bedin V, Baby AR, Velasco MVR. Thermal analysis of hair treated with oxidative hair dye under influence of conditioners agents. J Therm Anal Calorim. 2011;106(3):399-405.

Gama RM, Balogh TS, França S, Sá-Dias TC, Bedin V, Consiglieri VO, Kaneko TM, Baby AR, Velasco MVR. Evaluation of hair damage after treatments with light brown and light blond permanent dyes: hair protein loss determination. Braz J Pharm Sci. 2009;45(suppl.1):39.

Gulrajani ML. Colour measurement: principles, advances and industrial applications. London: Woodhead Publishing, 2010. $310 \mathrm{p}$.

Harrison S, Sinclair R. Hair colouring, permanent styling and hair structure. J Cosmet Dermatol. 2003;2(3/4):180-5.
Hoch D, Konrad E, Pasquier G, Mager H. Oxidative hair dye based on a low-viscosity carrier material. USA Patent US4,725,282 A. Wella Aktiengesellschaft; 1985.

Kostansek E. Emulsions. In: Kirk-Othmer. Chemical Technology of Cosmetics. New Jersey: John Wiley; 2012. p. 551-74.

Liu Y, Hong L, Wakamatsu K, Ito S, Adhyaru B, Cheng C, Bowers CR, Simon JD. Comparison of structural and chemical properties of black and red human hair melanosomes. Photochem Photobiol. 2005;81(1):135-44.

Nogueira ACS, Nakano AK, Joekes I. Impairment of hair mechanical properties by sun exposure and bleaching treatments. J Cosm Sci. 2004;55(4):533-7.

Nogueira ACS, Scanavez C, Carnelos C, Gaspari A, Joekes I. Hair color changes caused by dyeing and thermal treatments. J Cosm Sci. 2004;55(4):437-47.

Robbins CR, Crawford RJ. Cuticle damage and the tensile properties of human hair. J Soc Cosmet Chem. 1991;42(1):4958.

Robbins, CR. Chemical and physical behavior of human hair. v. 4. New York: Springer; 2002. p. 25-30.

Shansky A. A controllable progressive hair dye process. Cosmet Toil. 2007;122(1):67-72.

Tobin DJ. Human hair pigmentation - biological aspects. Int $\mathrm{J}$ Cosm Sci. 2008;30(2):233-57.

Velasco MVR, Sá-Dias TC, Freitas AZ, Vieira Junior ND, Pinto CASO, Kaneko TM, Baby AR. Hair fiber characteristics and methods to evaluate hair physical and mechanical properties. Braz J Pharm Sci. 2009;45(1):153-62.

Woodruff J. Improving hair strength. Cosmet Toil. 2002;117(3):33-6.

Received for publication on $20^{\text {th }}$ April 2017 Accepted for publication on $07^{\text {th }}$ August 2017 